\title{
Lower Lid and Face: Multispecialty Approach
}

Editors

BABAK AZIZZADEH

GUY G. MASSRY

Section Editors

STEVEN P. DAVISON

ANDREW JACONO

ROBERT M. SCHWARCZ

HEMA SUNDARAM

\section{CLINICS IN \\ PLASTIC SURGERY}

www.plasticsurgery.theclinics.com

January 2015 • Volume 42 - Number 1 